\title{
Study on the Development and Promotion of the Integrated Resource Database for the Training of Economic and Trade Teachers-A Case Study of Fuzhou University of International Studies and Trade
}

\author{
Siwei Dai ${ }^{1, *}$ \\ ${ }^{1}$ Fuzhou University of International Studies and Trade, Fuzhou, Fujian, 350202, China \\ * Corresponding author. Email: 3620964@qq.com
}

\begin{abstract}
This paper aims to solve the problem of the disconnection between the talent training and the social demand since the economic and trade undergraduate colleges "emphasize theories and neglect practical operation" whereas vocational colleges "focus on practical operation and make light of theories" in their talents training. Therefore, it is necessary to reform and promote the development of resources by relying on the teachers' training base at provincial level on the basis of vocational skills competition. In addition, it should actively enhance skills and update concepts of economic and trade teachers and improve the construction of teaching resources on software and teaching materials by "training through competitions and promoting teaching with competitions". By constructing such mode, we should actively organize the training of economic and trade teachers and carry out research on the reform of teaching concept, so as to form a complete set of training resource system for teachers in economic and trade vocational colleges.
\end{abstract}

Keywords: Economic and trade teachers; Teachers' training; Resources base; Training software

\section{INTRODUCTION}

With the advent of the "Internet plus" era, technologies, mobile Internet or Internet of Things, cloud computing technology or big data, have been widely applied in education industry and many other industries in a deeper way. In addition, with the constant changes in international trade rules and the continuous innovation of international trade forms, great changes have taken place in education and teaching, thus it is urgent to improve the training for economic and trade teachers. Systematic training is conducive to improving teachers' economic and trade knowledge. The foundation of establishing a complete training system is to develop an integrated resource database for teachers' training, which is an important basis for their training. However, there are still some shortcomings in the construction and application of the teaching resource database. Therefore, in view of this, this paper focuses on the construction of the platform of informationized teaching resource database and the construction of digital teaching resources and discusses and studies their application, so as to put forward corresponding solutions. [1]

\section{THE COURSE OF THE CONSTRUCTION OF INTEGRATED RESOURCE DATABASE FOR TEACHERS' TRAINING}

In 2011, the Ministry of Education issued Opinions on Further Improving the Training System for Vocational Teachers, which proposed to improve the school-enterprise cooperation mechanism of teachers' training bases, develop high-level projects and courses in combination with school advantages and training needs, and build a training brand. [2]

In order to implement such opinions, we should solve problems such as the old-fashioned concept, fragmentation, inapplicable training resources and the formality of the cultivation and training of economic and trade teachers in applied undergraduate and vocational colleges. Since 2012, together with perfect training condition in Fuzhou University of International Studies and Trade, rich experience in vocational education of Fuzhou Melbourne Polytechnic(the former IEN Institute of Minjiang University, hereinafter referred to as Fumo) and technological support from Fuzhou Jigao Information Technology Co., LTD.(hereinafter referred to as the Fuzhou Jigao), we developed a series of software integrating "training, teaching and competition", built a "professional, specialized and excellent" teachers' team for 
training, constructed a brand-new course modules, wrote and compiled a series of teaching materials and case base for training and established process evaluation mechanism "before training, during training and after training" on the basis of the training concept of "three-dimensional penetration" featuring "foreign trade quality + professional skills + the application of foreign language". Through tracking and summarizing the training effect of economic and trade teachers in colleges and universities in and out of the province, a set of integrated training resource database characterized by its "advanced concept, reasonable structure and scientific evaluation" has been finally formed.

Three course Modules for The Cand Training
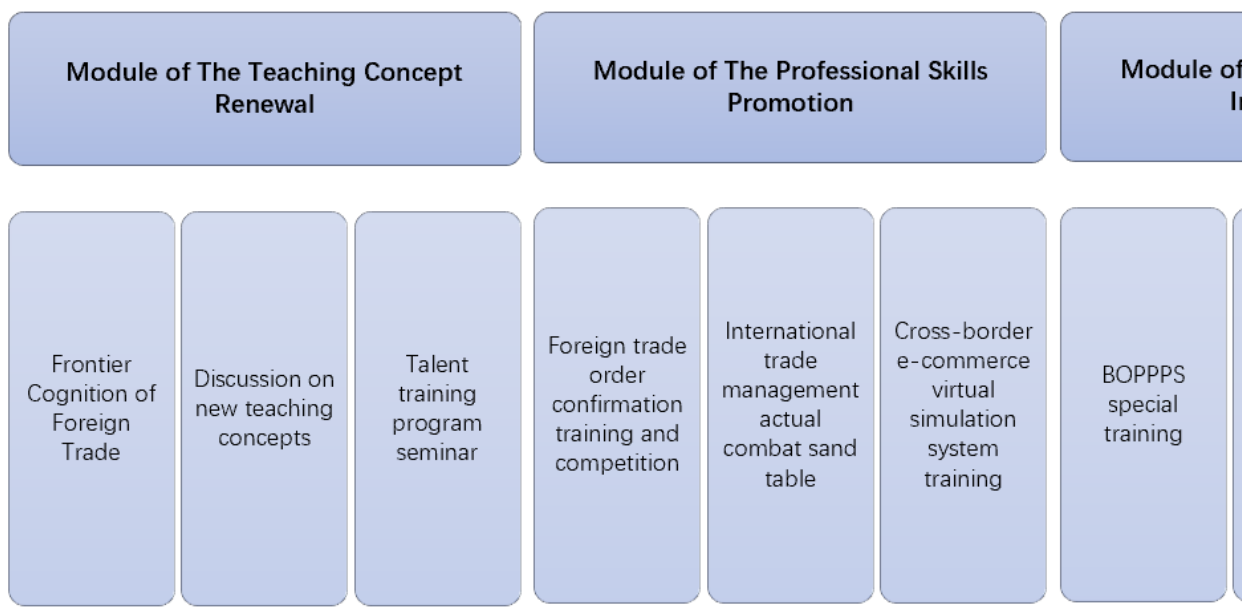

Module of The Teaching Method Improvements

Figure 1. Diagram of integrated resource database for cultivation and training
The software library, which is set in English, combines economic and trade theories with skills. It can be used for teachers' training, practical teaching and skill competition. It is of great help to improve teachers' economic and trade quality, professional skills and ability in using foreign language. Since 2014, the software library has been applied in the "Cross-Strait College Students Vocational Skills Competition" for the first time. It has supported such competition for six times, provided training services for more than 24,000 teachers and students from more than 100 universities and vocational colleges in more than 20 provinces and cities, and helped players win more than 200 gold awards and first prizes.

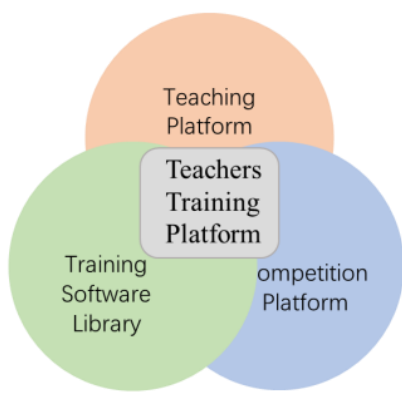

Figure 2. Diagram of the function of training software library
In 2017, relying on the integrated resources, it was successfully approved as "Teachers' Training Base of Provincial Vocational Education(Economic and Trade Category)" in Fujian Province. In 2019, the resource database was approved as "Teaching Resource Database for Professional Construction of Provincial Vocational Education". Through promotion and application in recent years, the content of the resource database has been constantly updated.

\section{THE MAIN PROBLEMS IN THE TRAINING OF ECONOMIC AND TRADE TEACHERS}

\subsection{Lagging Concept on Cultivation and Training}

With China's industrial upgrading and the proposition of the concept of open economic development, we have placed higher demand on the practical, inter-disciplinary and innovative talents who are what the economic and trade industry needs. The economic and trade undergraduate colleges "emphasize theories and neglect practical operation" whereas vocational colleges "focus on practical operation and make light of theories" in their 
talents training, which leads to the disconnection between the talent training and the social demand. Thus it is difficult to train high-quality talents to adapt to the development of the new era.

\subsection{Fragmented Cultivation and Training}

Traditional training methods are relatively undiversified and mainly limits to the offline course training for mostly foreign trade knowledge, which neither meets the needs of competition and teaching, nor achieves the dual improvement of theory and practical operation. Training courses are miscellaneous without a systematic practice, which impacts the effectiveness of training. "Fragmented" training randomly pieces together fragmented courses with seemingly gorgeous appearance, which brings joys to the participants, but only leaves a passing shadow. It is difficult to make a deep and lasting impression on their hearts. Such training is crammed with situational teaching with a mere formality. Thus students will inevitably be led by such situation, and the training objectives and training content can not be really achieved and implemented.

\subsection{Inapplicable Training Resources}

First, textbooks are full of theoretical content, and the cutting-edge professional knowledge is insufficient. The outdated content leads to the difficulty of talent cultivation to meet the needs of the current economic development. Second, we blindly pursue the recognition of new industries in terms of teaching software and attach importance to technology while making light of its application. The needs of the main users, such as teachers, students and social learners, are absent in the process of the design of teaching software. Therefore, in the construction process of teaching resource database for economic and trade majors, the demand is not clear enough. And there is a lack of multi-party participation and user interaction. The level of resource construction is low without an unified technical norms and construction standards and strong application. Third, with the wide application of information technology, digital teaching is promoting the reform of teaching rapidly. Information-based teaching resources are diversified with low quality. Most of the resources are made with low technical skills. The teaching materials cannot be fully applied in teaching, thus the value of sharing and promotion can not be achieved. And the teaching resources are not accessed to everyone. Furthermore, the resource base platform and function do not work completely, which is neither convenient for practical application, nor meet the demand.

\subsection{A Mere Formality for Cultivation and Training}

Teachers' training emerges one after another, with no specific objectives, superficial contents and little effect Many trainings focus on the form rather than the actual effect, and lack of effective evaluation mechanism. The training online that prevails in last few years is actually a very good form. Its training time is relatively free and teachers can manage their own time. In addition, its content is diverse and there is a lot of excellent expert teams and good network resources. Teachers can have gains if they are truly involved in training. But a lot of training only pay attention to the form, thus achieving little actual training effect. [3]

\section{COUNTERMEASURES AND SUGGESTIONS TO SOLVE THE PROBLEMS}

\subsection{We Should Come up with the Training Concept of "Three-Dimension Penetration"}

Guided by the demand of talents in the industry, the course training aims to cultivate the compound economic and trade talents who "know the major, understand foreign languages, be familiar with business and have strong practical ability". However, undergraduate teachers pay more attention to scientific research than practice, while vocational education teachers attach great importance to practice than theory, which leads to the disconnection between the cultivation of economic and trade talents and the social needs. The national requirements for the construction of high-level economic and trade majors cannot be met in terms of the teaching concept, skills and business foreign language application ability, thus we put forward new requirements for the construction of interdisciplinary teachers' team.

Based on training the inter-disciplinary teachers and aiming at the existing problem in the training of economic and trade teachers' team, we first put forward "three dimensional penetration" training concept characterized by "economic and trade quality, professional skills and foreign language application" in order to improve their knowledge on economics and trade, enhance professional skills and strengthen the foreign language application, thus fostering such inter-disciplinary teachers as pay equal attention to "theory and skills" and integrate economics and trade with the foreign language, which has been recognized and welcomed by teachers. 


\subsection{We Should Optimized the Curriculum and Improve the Effectiveness of Training}

In view of the shortcomings in application-oriented colleges and teachers for vocational education, we construct three curriculum modules of "teaching concept renewal, professional skills promotion and teaching method improvement". At the same time, according to the training tasks, we set up targeted and effective training courses and use multiple training methods in a comprehensive way such as combination of "classroom teaching, enterprise visit and special seminar", thus effectively improving training effect and quality. We have organized seminars on talent training programs and students' practical skills improvement for a total of 500 population with well-known enterprises and more than 20 universities such as Liaoning University and Fuzhou Melbourne Polytechnic.

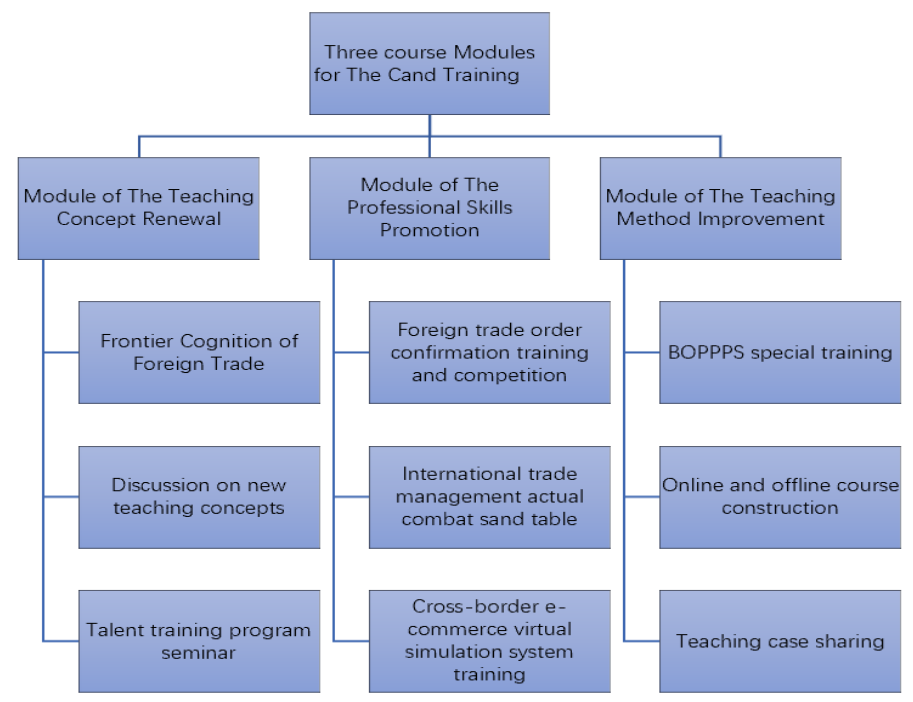

Figure 3. Three major course training modules

\subsection{We Should Build Resource Development Mode Combining "Schools and Enterprises"}

Training resources are preconditions for the normal training. Aiming at the problems in the training of economic and trade teachers: "lack of professional and technical system, lack of professional teachers for training, lack of professional training mode and lack of professional training course and teaching material", we adopt the linkage method between "schools and enterprises" and jointly develop integrated resource database for cultivation and training which is featured by "software, teachers' team, curriculum modules and related teaching material". Moreover, we effectively transform the training resources into teaching resources, update the cutting-edge contents and changes in economic and trade rules and standards brought by industrial and enterprise technological progress, simplify practical operation, which will be effectively integrated into the course teaching content, so as to improve the effectiveness of classroom teaching. In addition, we have built the integrated resource base which includes 4 sets of economic and trade operating systems integrating teaching, training and competition. We have built a profession team for training teachers which consists of more than 50 training teachers (including one committee member of Advisory Committee of Economic and Trade Teaching under the Ministry of Education, several expert professors, excellent teachers and experts from outside, etc.), compiled four supporting textbooks, established a set of process evaluation mechanism, and a series of extended training topics and courses. [4]

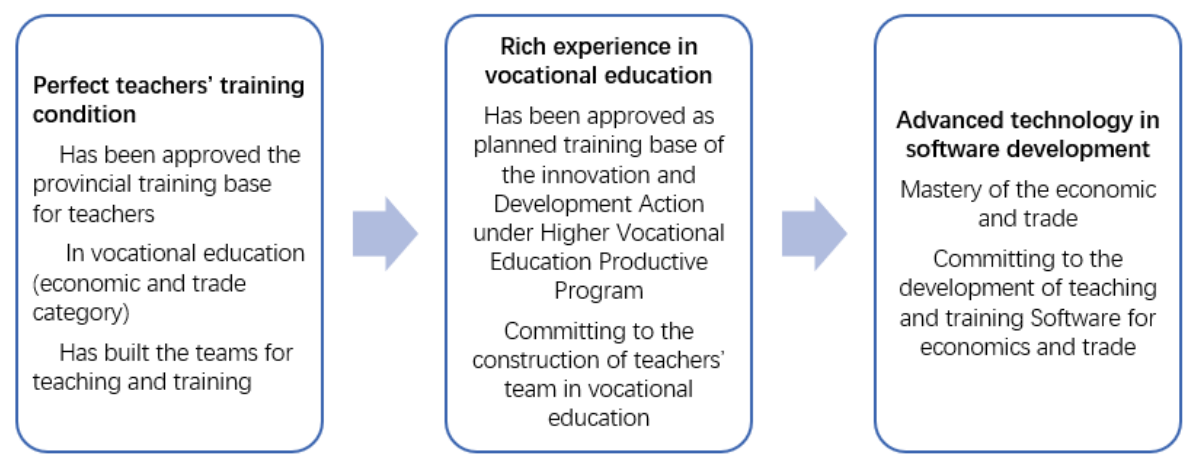

Figure 4. "School-Enterprise" cooperation mode 


\subsection{We Should Formulate the Evaluation Mechanism of "Pre-Training Investigation, In- Training Assessment and Post-Training Follow-Up".}

In order to scientifically evaluate the promotion of teachers' ability and their professional development brought by training, we pre-evaluate their initial ability state through the survey before the training, so as to understand their expectations for the ability improvement. In the process of training, we use the results to test the

\section{CONCLUSION}

After 6 years of practice, we have achieved remarkable results in the application of the integrated resource database. Meanwhile, we have effectively improved the teaching level of economic and trade vocational education in our province, reaped fruitful teaching resources, enhanced our ability in serving peer colleges, and exerted obvious influence on other colleges. We have trained a total of more than 500 teachers in the province, provided support to China Council for the Promotion of International Trade to train more than 1,000 economic and trade teachers in vocational colleges in 12 different training session on 6 topics such as "Frontier Understanding on Foreign Trade", "the Evolution of Foreign Trade Practice ", "Promoting Trade Facilitation and Liberalization". And more than 20 colleges and universities have enhanced their training in a total of 500 people in their talent training programs and students' practical improvement skills. And the efficiency of the resource receives unanimously praise. [6]

\section{ACKNOWLEDGMENT}

General projects of education reform at college level, Research on the Training Mode of "Three Creations" of International Business in Applied Colleges and Universities under the Background of New Liberal Arts, Project No.: JF2019016. quality of the training and judge whether the training can meet the needs of teachers' professional ability development. After training, we keep track of the state of their professional ability, which, on the one hand, can fully reflect the training results in the application and transformation of their work; on the other hand, can can avoid the distortion of the evaluation results caused by the long-period evaluation as well as the one of teachers' ability development caused by other factors other than training, thus ensuring the reliability and validity of the evaluation. [5]

\section{REFERENCES}

[1] COUSOT, P., \& COUSOT, R.. Abstract Interpretation Frameworks. Journal of Logic and Computation, 1992, 2(4), 511547.

doi:10.1093/logcom/2.4.511

[2] Freeman, D.. Teacher Training, Development, and Decision Making: A Model of Teaching and Related Strategies for Language Teacher Education. TESOL Quarterly, 1989, 23(1), pp. 27-45. doi: https://doi.org/10.2307/3587506

[3] Harris, D. N., \& Sass, T. R.. Teacher training, teacher quality and student achievement. Journal of Public Economics, 2011, 95(7-8), 798-812. DOI: https://doi.org/10.1016/j.jpubeco.2010.11.009

[4] Jourdan, D., Samdal, O., Diagne, F., \& Carvalho, G. S.. The future of health promotion in schools goes through the strengthening of teacher training at a global level. Promotion \& Education, 2008, 15(3), 36-38. doi: https://doi.org/10.1177/1025382308095657

[5] Seppälä, P.\& Alamäki, H.. Mobile learning in teacher training. Journal of Computer Assisted Learning, 2003, 19(3), 330-335. doi:10.1046/j.02664909.2003.00034.x

[6] Tiwari, A., Leung, W. C., Leung, T. W., Humphreys, J., Parker, B., \& Ho, P. C.. A randomised controlled trial of empowerment training for Chinese abused pregnant women in Hong Kong. BJOG: An International Journal of Obstetrics \& Gynaecology, 2005, 112(9), 1249-1256. doi:10.1111/j.14710528.2005.00709.x 